\title{
Morphological changes in placenta in cases of oligohydramnios
}

\author{
Amita Gupta, Sabha Musharaf, Gagan Singh*, Aakriti Gupta
}

Department of Obstetrics and Gynecology, Government Medical College, Jammu, Jammu and Kashmir, India

Received: 26 January 2018

Accepted: 28 February 2018

\author{
*Correspondence: \\ Dr. Gagan Singh, \\ E-mail: gaganbhau@gmail.com
}

Copyright: () the author(s), publisher and licensee Medip Academy. This is an open-access article distributed under the terms of the Creative Commons Attribution Non-Commercial License, which permits unrestricted non-commercial use, distribution, and reproduction in any medium, provided the original work is properly cited.

\section{ABSTRACT}

Background: There are gross and microscopic changes in placenta and umbilical cord in complicated pregnancies. The objective of this study was to study pathological (gross and microscopic) changes in placenta, membrane and umbilical cord in cases with oligohydramnios and to study relationship between changes in placenta, membranes and umbilical cord with severity of oligohydramnios.

Methods: A total of 50 patients were selected and their placentas were collected after delivery and sent to pathology department in $10 \%$ formalin for histopathological examination. Patients were divided into three groups and the results were compared. Statistical calculations were performed using the SPSS 16.0. In order to detect differences between subjects students t-test was used for continuous variables, while, for categorical variables, the X2 test was used. A p-value of less than 0.05 was considered statistically significant.

Results: Atotal of 50 patients were studied for a period of one year and following observations were made, discoid shape placenta in $45(90.0 \%)$, oval in $5(10.0 \%)$, central attachment of umbilical cord in 16 cases $(32.0 \%)$, eccentric in $33(66.0 \%)$, marginal in $1(2.0 \%)$ case following variables were compared and p value detected, placental maximum diameter $(\mathrm{p}<0.0001)$, placental minimum diameters $(\mathrm{p}=0.041)$, mean of cord length $(\mathrm{p}<0.0001)$ placental weight $(\mathrm{p}$ $=0.273)$, placental thickness $(\mathrm{p}=0.253)$, acute chorioamnionitis $(\mathrm{p}<0.0001)$, chronic chorioamnionitis $(\mathrm{p}<0.0001)$, focal squamous metaplasia ( $p<0.0001)$, bacterial colonies in subamnion ( $p<0.0001)$, meconium staining $(p<0.0001)$, amnion nodosum $(\mathrm{p}<0.0001)$, intra amniotic haemorrhage $(\mathrm{p}=0.090)$, membranous deciduitis with chorioamnionitis $(\mathrm{p}=0.081)$, focal haematoma $(\mathrm{p}=0.010)$, acute inflammatory infiltrate in Wharton's jelly $(\mathrm{p}=0.012)$, single umbilical artery $(\mathrm{p}=0.010)$, intervillous fibrin deposition $(\mathrm{p}<0.0001)$, calcification $(\mathrm{p}<0.0001)$, chorangiosis $(\mathrm{p}$ $<0.0001)$, syncytial knots $(\mathrm{p}<0.0001)$, avascular villi $(\mathrm{p}=0.011)$, villous edema $(\mathrm{p}=0.090)$ and infarct $(\mathrm{p}=0.090)$.

Conclusions: There are alterations in placental morphology associated with oligohydramnios hence placenta should be examined, which may be useful in predicting perinatal morbidity and mortality.

Keywords: Placenta, Oligohydromnios, Umbilical cord

\section{INTRODUCTION}

The term placenta is derived from Greek word 'PlakuosFlat cake' on the basis of its anatomical appearance. It carries out the function that the fetus is not able to perform during intrauterine life (functions of lungs, liver, endocrine organs and kidneys), the core function being the transport of nutrition. ${ }^{1}$ It is normally $15-22 \mathrm{~cm}$ in diameter, 2-4 cm in thickness, weighs 400-600 gm, blue red in colour and discoid in shape. ${ }^{2}$ It has two parts fetal and maternal. Maternal surface is rough and spongy, dull red in colour. It has 15-20 lobes or cotyledons. ${ }^{3}$ Umbilical cord is formed from fetal membranes. It is about 55$65 \mathrm{cms}$ in length and $2-2.5 \mathrm{cms}$ in thickness. ${ }^{4}$ Outer surface is covered by amnion and it contains two arteries and one vein. ${ }^{5}$ There are gross and microscopic changes in placenta and umbilical cord in complicated pregnancies. Grossly there is change in shape, size, 
weight, thickness of placenta and in umbilical cord there is change in length, thickness, amount of Wharton's jelly and number of vessels in it. ${ }^{6}$

Placenta in pre-eclampsia is triangular or kidney shaped; placenta is biparita or succenturiata in gestational diabetes mellitus; it is heart shaped in anemia and circumvallate or triangle shaped in preterm placenta. ${ }^{\text {? }}$ Grossly, characteristic lesion amnion nodosum is seen in cases of oligohydramnios. ${ }^{8}$ Amnion nodosum is characteristic lesion of oligohydramnios, fetal renal agenesis and pulmonary hypoplasia. ${ }^{9}$

On microscopic examination of placenta, basement membrane thickening, haemorrhagic vasculitis, thrombotic vasculopathy, syncytial knots are seen in cases of oligohydramnios. ${ }^{10}$ Fetal thrombotic vasculopathy is a placental lesion characterised by regionally distributed avascular villi and is often accompanied by upstream thrombosis in fetal vessels. It is associated with six times increased risk of oligohydramnios. ${ }^{11}$

Due to peculiar link between placenta and fetus any abnormality of cord, be it in the length, amount of wharton's jelly, number of vessels or its amniotic epithelium lead to abnormal fetal outcome. ${ }^{6}$ short cord is associated with oligohydramnios, fetal malformations, Down's syndrome, myopathies, neuropathies, less fetal activity, prolonged second stage of labour, cord rupture, breech presentation and placental abruption. ${ }^{12}$ Long cords are associated with cord thrombosis, entanglement, torsion as well as knot formation. ${ }^{2}$ Inadequate Wharton's jelly could lead to fetal death. ${ }^{12,2}$

Abnormalities in placental shape may be associated with $\mathrm{APH}$, preterm labour, retained placental tissue, fetal haemorrhage or oligohydramnios. In extreme circumvallate placenta the size of amniotic cavity may be restricted; leakage of amniotic fluid and oligohydramnios are sequelae and these in turn lead to compression abnormalities of fetus and pulmonary hypoplasia. ${ }^{13}$

Sonographic diagnosis of oligohydramnios is single largest pocket less than $2 \mathrm{~cm}$ and AFI less than $5 \mathrm{~cm}^{14,15}$ Amniotic fluid is generated from maternal plasma and passes through the fetal membranes by osmotic and hydrostatic forces and fetal vessels on placental surface. When fetal kidneys begin to function at about 8-11 weeks, fetal urine also contributes to the fluid.

Causes of oligohydramnios are divided into maternal, fetal and placental. Maternal causes are dehydration, diabetes, pre-eclampsia or chronic hypertension, collagen vascular disease and use of drugs like ACE inhibitors, ARBs. Fetal causes are growth restriction, gastrointestinal abnormalities, post-term pregnancy, fetal demise, PROM or PPROM, congenital anomalies and chromosomal abnormality such as Down's syndrome. Placental causes include placental abruption, placental thrombosis and infarction, uteroplacental insufficiency and twin-twin transfusion syndrome.

Many congenital anomalies are associated with oligohydramnios. Most cases of severely decreased amniotic fluid are secondary to genitourinary abnormalities. Anomalies may be unilateral or bilateral renal agenesis, bilateral multicystic dysplastic kidneys, bladder outlet obstruction, potter syndrome and pulmonary hypoplasia. ${ }^{16}$ Oligohydramnios may be associated with placental abnormalities and so this study was planned to know the morphological changes in placenta in cases of oligohydramnios.

\section{METHODS}

The present study was conducted in Department of Obstetrics and Gynaecology in collaboration with Department of Pathology, Government Medical College Jammu for a period of one-year November 2015 to October 2016. A total of 50 patients were selected according to inclusion criteria (singleton pregnancy, gestational age 28-40 weeks, intact membranes, no fetal anomalies on Ultrasonography and AFI $<5 \mathrm{~cm}$ on ultrasonography) and excluding all maternal and fetal causes of oligohydramnios (post-term pregnancy, multiple pregnancy, maternal intake of ace inhibitors, NSAIDS, PROM, Diabetes, pre-eclampsia and other hypertensive disorders, collagen vascular disease, TORCH infections, IUD fetus, renal disease).

Their placentas were collected after delivery and sent to Pathology Department in $10 \%$ formalin. Membranes examined for inflammation, decidual vasculopathy, exogenous substances, meconium, haemosiderin, various other pathological changes like fibrin deposits, calcification, and haemmorhagic cells. Umbilical cord was seen for number of arteries and veins, vasculitis, thrombosis and Wharton's jelly, fibrin, calcification, infarct. Parenchyma was seen for villous pattern, vasculopathy, thrombosis, infarcts, syncytial knots, calcification, infarct and fibrin deposition. Patients were divided into three groups based on AFI; mild with AFI $>4.1 \mathrm{~cm}$, moderate with $2.1-4.0 \mathrm{~cm}$ and severe with $\leq 2$ $\mathrm{cm}$ and the results were compared.

Statistical calculations were performed using the SPSS 16.0. Mean and standard deviation were determined for continuous variables. Categorical data were presented with absolute and relative frequencies. In order to detect differences between subjects students t-test was used for continuous variables, while, for categorical variables, the $X^{2}$ test was used. A p-value of less than 0.05 was considered statistically significant.

\section{RESULTS}

A total of 50 patients were studied based on inclusion and exclusion criteria for a period of one year and following observations were made, majority $(56 \%)$ were in age 
group of 21-25 years $($ Mean $=24.98 \pm 3.96), 62.0 \%$ were primigravida and $38.0 \%$ were multigravida, majority $(46.0 \%)$ were with gestational age of $38 \pm 40$ weeks (Mean $=37.78 \pm 1.77)$. The mean AFI was $3.77 \pm 1.05 \mathrm{~cm} .40 \%$ of placenta had a size of about $201-400 \mathrm{~cm}^{2}, 8.0 \%$ cases had size $\leq 200 \mathrm{~cm}^{2}($ mean $=462.84 \pm 223.71) .40 \%$ placentas had a weight of 301-400 gm and $4.0 \%$ had weight $>600$ gm $($ mean $=388.40 \pm 100.98) .26$ cases had cord length
$>31 \mathrm{~cm}$ and only 7 cases had $\leq 20 \mathrm{~cm}$ (mean $=$ 29.04 \pm 7.06$)$.

On gross examination, shape of placenta was discoid in 45 cases $(90.0 \%)$ and oval shape in $5(10.0 \%)$. Umbilical cord attachment was central in 16 cases (32.0\%), eccentric in 33 cases $(66.0 \%)$ and marginal in $1(2.0 \%)$ case.

Table 1: Association between placental morphometric variables with severity of oligohydramnios.

\begin{tabular}{|lllll|}
\hline Variables & Mild AFI $(\mathbf{n = 2 3})$ & Moderate AFI $(\mathrm{n}=20)$ & Severe AFI $(\mathrm{n}=7)$ & $\mathrm{p}$-value \\
\hline Placental weight $(\mathrm{g})$ & $387.83 \pm 84.58(200-600)$ & $407.50 \pm 110.50(300-800)$ & $335.71 \pm 118.02(200-500)$ & \\
\hline Placental max. diameter $(\mathrm{cm})$ & $16.30 \pm 1.89(14-20)$ & $14.03 \pm 1.14(12-16)$ & $10.60 \pm 0.38(10-11)$ & $<0.0001$ \\
\hline Placental min. diameter $(\mathrm{cm})$ & $12.59 \pm 3.10(5-16)$ & $11.39 \pm 2.03(8-15)$ & $9.86 \pm 1.35(7-11)$ & 0.041 \\
\hline Placental thickness $(\mathrm{cm})$ & $2.52 \pm 0.85(1-4)$ & $3.33 \pm 0.63(2-4)$ & $3.29 \pm 0.76(2-4)$ & 0.253 \\
\hline Cord length $(\mathrm{cm})$ & $33.76 \pm 5.33(21-42)$ & $27.33 \pm 4.73(18-35)$ & $18.43 \pm 2.37(15-21)$ & $<0.0001$ \\
\hline
\end{tabular}

Table 2: Association between microscopic examinations (placental membranes) with severity of oligohydramnios.

\begin{tabular}{|c|c|c|c|c|c|c|c|}
\hline \multirow{3}{*}{ Microscopic examination } & \multicolumn{6}{|c|}{ No. of cases (\%) } & \multirow{3}{*}{ p-value } \\
\hline & \multicolumn{2}{|c|}{ Mild AFI $(n=23)$} & \multicolumn{2}{|c|}{ Moderate AFI $(\mathbf{n}=\mathbf{2 0})$} & \multicolumn{2}{|c|}{ Severe AFI $(n=7)$} & \\
\hline & No. & $\%$ & No. & $\%$ & No. & $\%$ & \\
\hline Intraamniotic haemorrhage & 1 & 4.35 & 1 & 5.00 & 0 & 0.00 & 0.090 \\
\hline $\begin{array}{l}\text { Membranous deciduitis with } \\
\text { chorioamnionitis }\end{array}$ & 4 & 17.39 & 3 & 15.00 & 2 & 28.57 & 0.081 \\
\hline Chronic chorioamnionitis & 0 & 0.00 & 1 & 5.00 & 1 & 14.29 & $<0.0001$ \\
\hline Focal squamous metaplasia & 0 & 0.00 & 3 & 15.00 & 0 & 0.00 & $<0.0001$ \\
\hline Bacterial colonies in sub amnion & 0 & 0.00 & 1 & 5.00 & 1 & 14.29 & $<0.0001$ \\
\hline Acute chorioamnionitis & 0 & 0.00 & 2 & 10.00 & 2 & 28.57 & $<0.0001$ \\
\hline Meconium staining & 0 & 0.00 & 2 & 10.00 & 2 & 28.57 & $<0.0001$ \\
\hline Amnion nodosum & 1 & 4.35 & 1 & 5.00 & 2 & 28.57 & $<0.0001$ \\
\hline
\end{tabular}

Table 3: Association between microscopic examinations (membrane) with severity of oligohydramnios.

\begin{tabular}{|c|c|c|c|c|c|c|c|}
\hline \multirow{3}{*}{ Microscopic examination } & \multicolumn{6}{|c|}{ No. of cases $(\%)$} & \multirow{3}{*}{ p-value } \\
\hline & \multicolumn{2}{|c|}{$\begin{array}{l}\text { Mild AFI } \\
(\mathbf{n}=\mathbf{2 3})\end{array}$} & \multicolumn{2}{|c|}{$\begin{array}{l}\text { Moderate AFI } \\
(\mathbf{n}=\mathbf{2 0})\end{array}$} & \multicolumn{2}{|c|}{$\begin{array}{l}\text { Severe AFI } \\
(\mathbf{n}=7)\end{array}$} & \\
\hline & No. & $\%$ & No. & $\%$ & No. & $\%$ & \\
\hline Focal haematoma & 0 & 0.00 & 1 & 5.00 & 0 & 0.00 & 0.010 \\
\hline Acute inflammatory infiltrate in Wharton's jelly & 1 & 4.35 & 0 & 0.00 & 0 & 0.00 & 0.012 \\
\hline Single umbilical artery & 0 & 0.00 & 1 & 5.00 & 0 & 0.00 & 0.010 \\
\hline
\end{tabular}

Table 4: Association between microscopic examinations (membrane) with severity of oligohydramnios.

\begin{tabular}{|c|c|c|c|c|c|c|c|}
\hline \multirow{3}{*}{ Microscopic examination } & \multicolumn{6}{|c|}{ No. of cases (\%) } & \multirow{3}{*}{ p-value } \\
\hline & \multicolumn{2}{|c|}{$\begin{array}{l}\text { Mild AFI } \\
(\mathbf{n}=\mathbf{2 3})\end{array}$} & \multicolumn{2}{|c|}{$\begin{array}{l}\text { Moderate AFI } \\
(\mathbf{n = 2 0})\end{array}$} & \multicolumn{2}{|c|}{$\begin{array}{l}\text { Severe AFI } \\
(n=7)\end{array}$} & \\
\hline & No. & $\%$ & No. & $\%$ & No. & $\%$ & \\
\hline Intervillous fibrin deposition & 11 & 47.83 & 16 & 80.00 & 6 & 85.71 & $<0.0001$ \\
\hline Avascular villi & 1 & 4.35 & 0 & 0.00 & 0 & 0.00 & 0.011 \\
\hline Calcification & 6 & 26.09 & 8 & 40.00 & 4 & 57.14 & $<0.0001$ \\
\hline Chorangiosis & 1 & 4.35 & 2 & 10.00 & 2 & 28.57 & $<0.0001$ \\
\hline Syncytial knots & 7 & 30.34 & 9 & 45.00 & 5 & 71.23 & $<0.0001$ \\
\hline Villous edema & 1 & 4.35 & 1 & 5.00 & 0 & 0.00 & 0.090 \\
\hline Infarct & 0 & 0.00 & 1 & 5.00 & 1 & 14.29 & 0.090 \\
\hline
\end{tabular}


On comparing placental morphometric variables (Table 1), placental maximum diameter ( $\mathrm{p}$ value <0.0001), placental minimum diameters $(\mathrm{p}$ value $=0.041)$ and the mean of cord length ( $p$ value $<0.0001$ ) was found statistically significant while Placental weight $(\mathrm{p}$ value $=$ 0.273 ) and placental thickness ( $p$ value $=0.253$ ) was found statistically insignificant.

On microscopic examination of placental membranes (Table 2), umbilical cord (Table 3) and placental disc (Table 4), acute chorioamnionitis ( $\mathrm{p}$ value <0.0001), Chronic chorioamnionitis ( $\mathrm{p}$ value $<0.0001$ ), Focal squamous metaplasia ( $p$ value $<0.0001$ ), bacterial colonies in subamnion ( $p$ value $<0.0001$ ), Meconium staining ( $\mathrm{p}$ value $<0.0001$ ) and amnion nodosum ( $\mathrm{p}$ value $<0.0001)$ was found significant while intra amniotic haemorrhage ( $\mathrm{p}$ value $=0.090)$ and membranous deciduitis with chorionitis $(p$ value $=0.081$ ) was found insignificant, focal haematoma ( $\mathrm{p}$ value $=0.010$ ), acute inflammatory infiltrate in Wharton's jelly (p value $=0.012$ ) and single umbilical artery ( $\mathrm{p}$ value $=$ 0.010) was found significant, intervillous fibrin deposition ( $\mathrm{p}$ value <0.0001), calcification ( $\mathrm{p}$ value $<0.0001$ ), chorangiosis ( $\mathrm{p}$ value $<0.0001$ ), syncytial knots ( $\mathrm{p}$ value $<0.0001$ ) and avascular villi ( $\mathrm{p}$ value 0.011 ) was found statistically significant while villous edema ( $p$ value $=0.090)$ and infarct ( $\mathrm{p}$ value $=0.090$ ) was found insignificant.

\section{DISCUSSION}

On comparing placental morphometric variables among 3 groups following observations were made, maximum diameter of placenta ( $\mathrm{p}$ value $<0.0001$ ), minimum diameters of placenta $(\mathrm{p}$ value $=0.041)$ and umbilical cord length was found significant ( $\mathrm{p}$ value $<0.0001$ ) which was consistent with study conducted by Spinillo A et al, ( $p$ value $<0.0001)$ placental thickness ( $p$ value $=$ 0.253 ) Spinillo A et al, 2015 ( $\mathrm{p}$ value $=0.06$ ) and mean weight of placenta $(p$ value $=0.273)$ was found insignificant. ${ }^{17}$

In the present study, on gross examination $90.0 \%$ cases had discoid shaped and $10.0 \%$ cases had oval shaped placenta which was consistent with study of Hamdany $\mathrm{MZ}$, in which discoid shape was seen in all cases of oligohydramnios. $^{18}$

On microscopic examination of placental membranes following findings were found significant in the present study, chronic chorioamnionitis ( $p$ value $<0.0001$ ), acute chorioamnionitis ( $\mathrm{p}$ value $<0.0001$ ), meconium staining ( $p$ value $<0.0001$ ) which was consistent with Spinillo A et al, ( $\mathrm{p}$ value $<0.0001$ ) and with Nath J et al, who found that $30.76 \%$ (24) cases had meconium stained liquor in patients with oligohydramnios, amnion nodosum ( $\mathrm{p}$ value $<0.0001$ ) consistent with study conducted by Devi $\mathrm{H}$ et al and by Adeniran AJ et al who found that amnion nodosum was present in $22.2 \%$ cases in study group compared to $4.4 \%$ cases in control group, focal squamous metaplasia ( $\mathrm{p}$ value $<0.0001$ ) and bacterial colonies in subamnion ( $\mathrm{p}$ value <0.0001) while membranous deciduitis with chorioamnionitis $(\mathrm{p}$ value $=0.081)$ and intraamniotic haemorrhage $(\mathrm{p}$ value $=0.090)$ was found insignificant. ${ }^{19,10,20}$

On microscopic examination of umbilical cord, only 1 case had single umbilical artery ( $p$ value $=0.010$ ). It may be associated with malformation and when malformation excluded, may be associated with low birth weight (Deborah I et al). ${ }^{21}$ Focal haematoma was seen in only 1 case ( $p$ value 0.010) It is associated with increased perinatal mortality to the extent of $40-50 \%$ when ruptures with significant fetal haemorrhage (Deborah I et al). ${ }^{21}$ acute inflammatory infiltrate in Wharton's jelly was seen only in 1 case ( $\mathrm{p}$ value $=0.012$ ).

On microscopic examination of placental disc following findings were found significant in our study, Intervillous fibrin deposition ( $p$ value $<0.0001$ ) which was consistent with Spinillo A et al, ( $p$ value $<0.0001$ ) and with Hamadany MZ, in which extensive stromal fibrin deposition was seen with statistically significant difference between study and control group, syncytial knots ( $\mathrm{p}$ value $<0.0001$ ) consistent with Hamdany A, in which $55 \%$ of cases had syncytial knots compared to $25 \%$ control, Devi $\mathrm{H}$ et al in which $53 \%$ cases of oligohydramnios had syncytial knots and with Spinillo et al, 2015 ( $p$ value $<0.0001$ ), calcification ( $p$ value of $<0.0001$ ) consistent with Zhang L et al, who found that incidence of oligohydramnios was $26.67 \%$ compared to control group $6.49 \%$, p-value $<0.05$ in placentas with premature aging, chorangiosis ( $p$ value $<0.0001$ ) and Avascular villi ( $\mathrm{p}$ value $=0.011$ ) consistent with Redline RW et al, who found association of avascular villi to increased rate of IUGR and oligohydramnios. ${ }^{18,10,17,22,23}$

Villous edema $(\mathrm{p}$ value $=0.090)$ and infarct $(\mathrm{p}$ value $=$ 0.090) consistent with Spinillo A et al, 2015 in which infarct (early) was found in $15.6 \%$ cases in mild, $13.6 \%$ cases in moderate and $11.2 \%$ cases in severe oligohydramnios group $(\mathrm{p}$ value $=0.25$ ) was found insignificant. $^{17}$

\section{CONCLUSION}

The study concluded that in cases of oligohydramnios, there was reduction in weight, size of placenta and length of umbilical cord although shape of placenta and cord attachment was not affected. On microscopic examination, various lesions were found depicting increased maturity of placenta, inflammation, abruption, meconium staining and amnion nodosum. All of them were associated with increasing severity of oligohydramnios and the association was statistically significant in the present study. This indicates that there are alterations in placental morphology associated with oligohydramnios hence placenta should be examined, which may be useful in predicting perinatal morbidity and mortality. 
Funding: No funding sources

Conflict of interest: None declared

Ethical approval: The study was approved by the Institutional Ethics Committee

\section{REFERENCES}

1. Pijnenberg, Bland R, Robertson JM, Brossens WB. Uteroplacental arterial changes related to interstitial trophoblast migration in early human pregnancy. Placenta. 1983;4:387-414.

2. Yetter JF. Examination of placenta. Am Family Phy. 1998;57(5):1045-54.

3. Borton C. Placenta and placental problems. Patient Plus. 2006;20:159.

4. Salafia C, Vintziloes AM. Why all placentae should be examined by pathologist. Am J Obstet Gynaecol. 1999;163(4):1282-93.

5. Kulkarni ML, Matadu SP, Ashok C, Pradeep N, Avinash T, Kulkarni AM. Absence of Wharton's jelly around the umbilical arteries. Indian J Paediatr. 2007;74(8):787-89.

6. Leung AK, Robson WL. Single umbilical artery, report of 159 cases. Am J Child Dis. 1989;143(1):108-11.

7. Sudha R, Sivakumar V, Jebakani F. Study of shape of placenta and its relation to placental weight in normal and complicated - pregnancy. Nat $\mathrm{J}$ Basic Med Sci. 2012;2(4):307-11.

8. Sepulveda W. Velamentous insertion of umbilical cord: a first trimester sonographic screening study. J Ultrasound Med. 2006;25(8):963-8.

9. Ziadie M, Kowalski PJ. Placental gross/microscopic abnormalities, non-neoplastic Amnion nodosum. 2011. Available at http://www.pathologyoutlines.com/topic/placentaam nionnodosum.html

10. Devi H, Uma N. Prospective study of correlation between perinatal outcome and histopathology of placenta in cases of oligohydramnios. J Evidence Based Med Healthcare. 2015;2(5):493-504.

11. Saleemudin A, Tantbirojn P, Kathleen S. Obstetric and perinatal complication in placentas with fetal thrombotic vasculopathy. Paediatr Dev Pathol. 2010;13(6):459-64.

12. Hefetz SA. The umbilical cord obstetrically important lesions. Clin Obstet Gynaecol. 1996;39:87.
13. Suzuki S. Clinical significance of pregnancies with circumvallate placenta. J Obstet Gynaecol Res. 2008;34(1):51-4.

14. Manning AF, Platt LD, Sipos L. Antepartum fetal evaluation: development of fetal biophysical profile. Am J Obstet Gynecol. 1980;136(6):787-95.

15. Phelan JP, Smith CV, Small M. Amniotic fluid volume assessment with the four- quadrant technique at 36-42 weeks gestation. J Reprod Med. 1987;32:540-2.

16. Stoll C, Alembik Y, Roth MP, Dott B. Study of 224 cases of oligohydramnios and congenital malformations in a series of 225,669 consecutive births. Community Genet. 1998;1(2):71-7.

17. Spinillo A, Cesari S, Bariselli S, Tzialla C, Gardella B, Silini EM. Placental lesions associated with oligohydramnios in fetal growth restricted pregnancies. Placenta. 2015;36(5):538-44.

18. Hamdany MZ. To study effects of oligohydramnios on histological structure of full term placenta. Tikrit Med J. 2008;14(2):156-69.

19. Nath J, Jain M, Najam R. A clinical study on oligohydramnios in the third trimester of pregnancy with special emphasis on the perinatal outcome. J Evol Med Dent Sci. 2013;2(39):7386-91.

20. Adeniran AJ, Stanek J. Amnion nodosum revisited: clinicopathologic and placental correlations. Arch Pathol Lab Med. 2007;131(12):1829-33.

21. Deborah I, Gersell, Frederick TK. Diseases of placenta. Blaustein's pathology of the female genital tract, $6^{\text {th }}$ edition. Springer; 2011;19:1000-1069.

22. Zhang $\mathrm{L}, \mathrm{Yu} \mathrm{YH}, \mathrm{Hu}$ MH. Association between ultrasonographic signs of placental premature aging and pregnancy outcome. Acad J First Med College PLA. 2005;25(3):318-20.

23. Redline RW, Pappin A. Fetal thrombotic vasculopathy: the clinical significance of extensive avascular villi. Hum Pathol. 1995;26(1):80-5.

Cite this article as: Gupta A, Musharaf S, Singh G, Gupta A. Morphological changes in placenta in cases of oligohydramnios. Int J Reprod Contracept Obstet Gynecol 2018;7:1518-22. 